\title{
Zeta Potential of Various Oxide Particles and the Charging Mechanism
}

\author{
Yoshinori TAKAYAMA, Hideyuki NEGISHI, Satoshi NAKAMURA, Nobuyuki KOURA, \\ Yasushi IDEMOTO and Fumio YAMAGUCHI \\ Department of Industrial Chemistry, Faculty of Science and Technology, Tokyo University of Science, \\ 2641, Yamazaki, Noda-shi, Chiba 278-8510
}

\author{
各種酸化物粒子の $\zeta$ 電位と帯電機構 \\ 高山佳典・根岸秀之・中村 聡 - 小浦延幸・井手本＼cjkstart康・山口文雄 \\ 東京理科大学理工学部工業化学科, 278-8510 千葉県野田市山崎 2641
}

\begin{abstract}
The charging behavior of various oxide particles was investigated using the zeta potential, which is affected by the electronegativity of the metal ion in an oxide and the properties of the solvents. Acetone, methylethylketone, cyclohexanone, ethanol (EtOH), 1-propanol (1-PrOH) and 1-butanol (1-BuOH) were used for the bath. In the case of the $\mathrm{I}_{2}$-added ketone bath, the $\mathrm{H}^{+}$ion concentration increased with increasing $I_{2}$ content. The zeta potential of the various oxide particles was changed to positive. The zeta potential of the oxides was large in the high $\mathrm{H}^{+}$ion concentration bath. Accordingly, the positive charged oxide particles were attributed to the adsorption of $\mathrm{H}^{+}$ion onto the particles. In the case of alcohol, included $\mathrm{H}_{2} \mathrm{O}$ generates $\mathrm{H}^{+}$and $\mathrm{OH}^{-}$by electrolytic dissociation. Therefore, the zeta potential becomes large in the case when the electronegativity of the metal ion in oxide is low, and the $\mathrm{H}^{+}$ion behaves as a potential determining ion.

[Received September 1, 1998; Accepted December 3, 1998]
\end{abstract}

Key-words : Oxide particle, Zeta potential, Electronegativity, Solvents

\section{Introduction}

The advantages of the electrophoretic deposition method are: (1) obtaining a uniform and dense coating in a short time, (2) easy control of the thickness and the density of the coating by the deposition voltage and time. ${ }^{1)}$ Therefore, coatings can be obtained on various shapes and size substrates by this method. Several studies using this method are now being conducted. ${ }^{1)}$ In this method, oxide particles must be charged in the electrophoretic deposition bath. The charging mechanisms of the particles in an aqueous polar solvent, ${ }^{2)}$ nonaqueous nonpolar solvent ${ }^{2)}$ and nonaqueous polar solvent ${ }^{3), 4}$ ) have been reported. Generally, the charging magnitude of the oxide is affected by the amount of potential determining ion, dielectric constant of the solvent and ion concentration. ${ }^{2)}$ The charging magnitude is estimated by the zeta potential.

In our previous paper, ${ }^{5)}$ it was explained that the charging mechanism was related not only the dielectric constant of the solvent and the potential determining ion concentration but also the adsorption of $\mathrm{H}^{+}$ion on the particles and electronegativities of the metal ions in the oxides such as $\mathrm{YBa}_{2} \mathrm{Cu}_{3} \mathrm{O}_{7-\delta}$ and $\mathrm{BaTiO}_{3}{ }^{5}{ }^{5}$ ) The solvent was acetone with $\mathrm{I}_{2}$ in order to generate $\mathrm{H}^{+}$ions.

In this paper, we attempted to explain this charging mechanism that is related to the adsorption of $\mathrm{H}^{+}$ion as the potential determining ion and the electronegativity of the metal ion in the oxide in various solvents. The solvents used were $\mathrm{I}_{2}$-added ketone and alcohol as the protic solvent. These solutions contained a small amount of $\mathrm{H}_{2} \mathrm{O}$ because of the electrolytic dissociation.

\section{Experimental}

The average particle size of the oxide is about $3 \mu \mathrm{m}$. Reagent grade organic solvents from Wako Pure Chemical Industries, Ltd., Osaka, Japan, were used. The physical properties of the organic solvents are shown in Table 1. These organic solvents were dehydrated using molecular sieves, and the $\mathrm{H}_{2} \mathrm{O}$ contents of the organic solvents were measured using a Karl Fisher Moisture Titrator (Kyoto Electric, Inc., MKA-3P). For the determination of the $\mathrm{H}^{+}$
Table 1. Physical Properties of Organic Solvents ${ }^{6), 9)}$

\begin{tabular}{lccc}
\hline \hline $\begin{array}{c}\text { organic } \\
\text { solvents }\end{array}$ & $\begin{array}{c}\text { relative } \\
\text { dielectric } \\
\text { constant }\end{array}$ & $\begin{array}{c}\text { viscosity } \\
\text { (cP) }\end{array}$ & $\begin{array}{c}\text { enol type } \\
(\%)\end{array}$ \\
\hline acetone & 20.7 & 0.322 & $1.5 \times 10^{-4}$ \\
methylethlyketone & 18.5 & 0.441 & $1.2 \times 10^{-4}$ \\
cyclohexanone & 18.3 & 2.453 & 1.2 \\
ethanol & 24.3 & 1.19 & - \\
1-propanol & 20.1 & 2.20 & - \\
1-butanol & 17.5 & 2.95 & - \\
\hline
\end{tabular}

ions in a bath, a neutralization titration was performed using a $0.01 \mathrm{~N} \mathrm{NaOH}$ solution after an excess of $\mathrm{Na}_{2} \mathrm{~S}_{2} \mathrm{O}_{3}$ was added in order to remove the residual $\mathrm{I}_{2}$. ${ }^{5}$ The conductivity of the baths was measured at $25^{\circ} \mathrm{C}$ using a conductivity meter (TOA Electronics, Ltd.). The zeta potential of an oxide (oxide concentration: $0.01 \mathrm{~g} / 1$ ) was measured at $25^{\circ} \mathrm{C}$ using an automated electrokinetics analyzer (Pen Kem, System 3000).

\section{Results and discussion}

3.1 Zeta potential in ketone baths

3.1.1 Zeta potential with the addition of $\mathrm{I}_{2}$ and $\mathrm{H}_{2} \mathrm{O}$

The acetone molecule generated an $\mathrm{H}^{+}$ion through interaction with the additive $\mathrm{H}_{2} \mathrm{O}$ and $\mathrm{I}_{2}$ :

$$
\begin{aligned}
& \mathrm{H}_{2} \mathrm{O}, \mathrm{I}_{2} \\
& \mathrm{CH}_{3} \mathrm{COCH}_{3} \rightleftarrows \mathrm{CH}_{3} \mathrm{C}(\mathrm{OH}) \mathrm{CH}_{2} \\
& \mathrm{CH}_{3} \mathrm{C}(\mathrm{OH}) \mathrm{CH}_{2}+\mathrm{I}_{2} \\
& \longrightarrow \mathrm{CH}_{3} \mathrm{COCH}_{2} \mathrm{I}+\mathrm{H}^{+}+\mathrm{I}^{-}
\end{aligned}
$$

It is assumed that the generated $\mathrm{H}^{+}$ion is adsorbed on the surface of the metal oxide particles. ${ }^{7)}$ The surface of an oxide has a hydroxyl group due to chemical adsorption. The electrification process is drawn in Fig. 1.8) In our previous study, the zeta potentials of the particles in an $\mathrm{I}_{2}$-added acetone were positive because of the adsorption of $\mathrm{H}^{+}$ion..$\left.^{5}\right)$

Therefore, this mechanism was applied not only to 


\section{Surface of oxide particle}

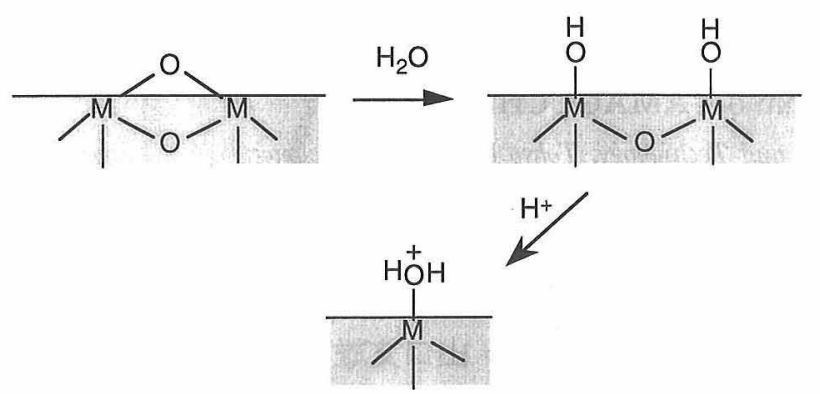

Fig. 1. A schematic model for the formation of surface hydroxyl group and the electrification process. ${ }^{8)}$

acetone but also to the other ketone containing $I_{2}$ in order to generate $\mathrm{H}^{+}$ion as in Eq. (2). It is known that the percent of the keto-type and enol-type differs with the ketone as shown in Table 1.9) The $\mathrm{H}^{+}$ion concentrations increased with increasing concentration of $\mathrm{I}_{2}$ as shown in Fig. 2. It is concluded that the formation of $\mathrm{H}^{+}$ion is based on ketoenol tautomerism like acetone in methylethylketone and cyclohexanone. Experimentally, in the case when the dielectric constant of the solvent is large, the ion is stabilized by solvation and the ion concentration increases. Therefore, the large order of the $\mathrm{H}^{+}$ion concentration as a result of reaction between the enol-type ketone and $I_{2}$ is the same as that of the dielectric constant.

The adsorption of $\mathrm{H}^{+}$ion onto the oxide particle in $\mathrm{I}_{2-}$ added ketone was then investigated. In Fig. 3 , the white marks show the conductivities of the oxide-free baths. The conductivity increased with increasing $\mathrm{H}^{+}$ion concentration. The order of the conductivity for the solutions was opposite to that of the $\mathrm{H}^{+}$ion concentration. It is considered that acetone has a relatively high dielectric constant and a low viscosity, therefore, the ions easily move in the bath. For the addition of $\alpha-\mathrm{Al}_{2} \mathrm{O}_{3}$ in ketone with $\mathrm{I}_{2}$, the conductivity of the baths decreased (Fig. 3). In the case of $\mathrm{I}_{2}$-free bath, the conductivity was increased to about $10^{-7}-10^{-6}$ $\mathrm{S} \cdot \mathrm{cm}$ by the addition of $\alpha-\mathrm{Al}_{2} \mathrm{O}_{3}$. It has been assumed that the conductivity of the bath is affected by the decrease in ion concentration due to the adsorption of the ion onto the oxide rather than by the addition of $\alpha-\mathrm{Al}_{2} \mathrm{O}_{3}$. In this case, the zeta potential of oxide may be changed.

Accordingly, the zeta potential of the various oxide particles was measured in the acetone, methylethylketone and cyclohexanone with the different amounts of $I_{2}$ (Fig. 4). These solvents contained about $0.13 \mathrm{~mol} / 1 \mathrm{H}_{2} \mathrm{O}$. In the case of the $\mathrm{I}_{2}$-free baths, the zeta potential of the various oxide particles is near $0 \mathrm{mV}$ or negative. It is likely that the oxygen on an oxide surface is charged partially $\left(\mathrm{M}\left(\delta^{+}\right)-\mathrm{O}\left(\delta^{-}\right)\right)$ and the ion concentration is very low in pure organic solvent. Therefore, the zeta potential of oxide is $0 \mathrm{mV}$ or negative. With the addition of $\mathrm{I}_{2}$ to the bath, the zeta potential rapidly increased and became positive. It was considered that the $\mathrm{H}^{+}$ion generated by the addition of $\mathrm{I}_{2}$ was adsorbed onto the surface of the oxide particles.

Moreover, the relationship of the zeta potential and the amount of $\mathrm{H}_{2} \mathrm{O}$ were measured as shown in Fig. 5. Small amounts of $\mathrm{H}_{2} \mathrm{O}$ in organic solvent are needed as a catalyst in Eq. (1). The zeta potential of these oxides increased with a small addition of $\mathrm{H}_{2} \mathrm{O}$. However, by adding more $\mathrm{H}_{2} \mathrm{O}$, the zeta potential decreased. In the case of cyclohexanone, the two phases separated over $0.5 \mathrm{~mol} / 1 \mathrm{H}_{2} \mathrm{O}$. The zeta potential was influenced by the amount of $\mathrm{I}_{2}$ and $\mathrm{H}_{2} \mathrm{O}$ because these are related to the reaction by the formation of $\mathrm{H}^{+}$ion (Eqs. (1) and (2)). Generally, if the ion concentra-

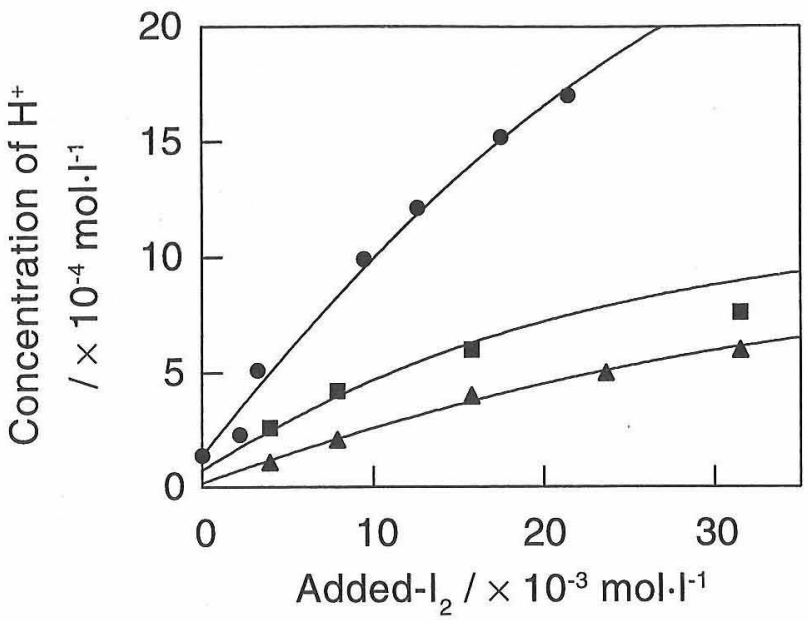

Fig. 2. Change of $\mathrm{H}^{+}$concentration with the amount of added- $\mathrm{I}_{2}$. $\Delta:$ in acetone bath, $\square:$ in methylethylketone bath, $\bigcirc:$ in cyclohexanone bath.

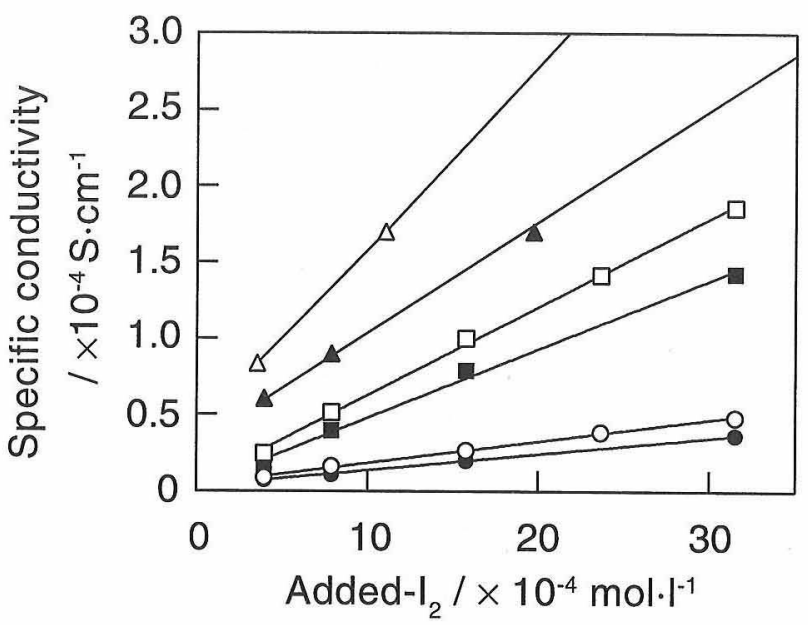

Fig. 3. Change of specific conductivity with the amount of added$\mathrm{I}_{2} \cdot \triangle$ : acetone, $\Delta$ : acetone with $\mathrm{Al}_{2} \mathrm{O}_{3}$ powder $(20 \mathrm{~g} / 1)$, $\square$ : methylethylketone, $\square$ : methylethylketone with $\mathrm{Al}_{2} \mathrm{O}_{3}$ powder $(20 \mathrm{~g} / \mathrm{l}), \mathrm{O}$ : cyclohexanone, $\mathrm{:}$ cyclohexanone with $\mathrm{Al}_{2} \mathrm{O}_{3}$ powder $(20 \mathrm{~g} / 1)$.

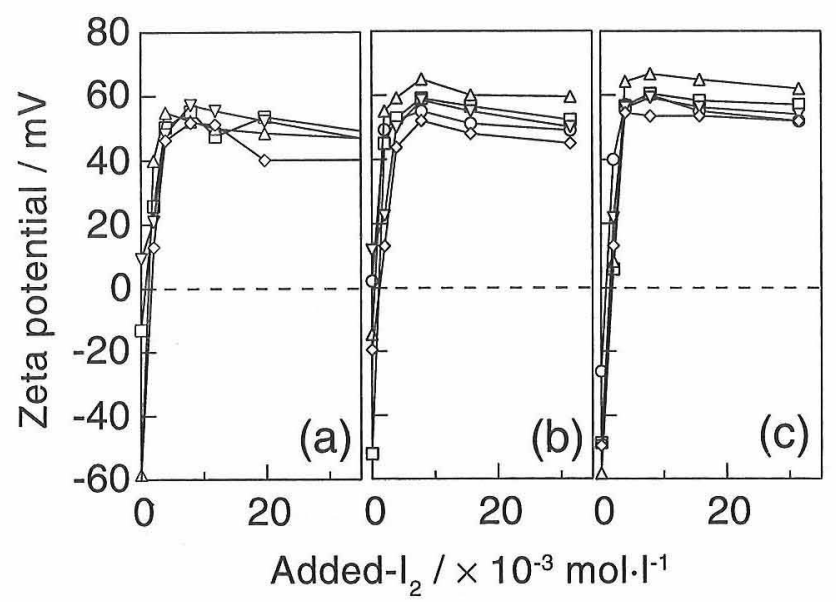

Fig. 4. Change of the zeta potential of various oxide powders with the amount of added- $\mathrm{I}_{2}\left(\mathrm{H}_{2} \mathrm{O}: 0.13 \mathrm{~mol} / \mathrm{l}\right)$. (a) acetone, (b) methylethylketone, (c) cyclohexanone, oxide powder: $20 \mathrm{~g} / 1$, $\mathrm{O}: \mathrm{MgO}, \square: \mathrm{Al}_{2} \mathrm{O}_{3}, \triangle: \mathrm{Cr}_{2} \mathrm{O}_{3}, \nabla: \mathrm{TiO}_{2}, \diamond: \mathrm{WO}_{3}$. 


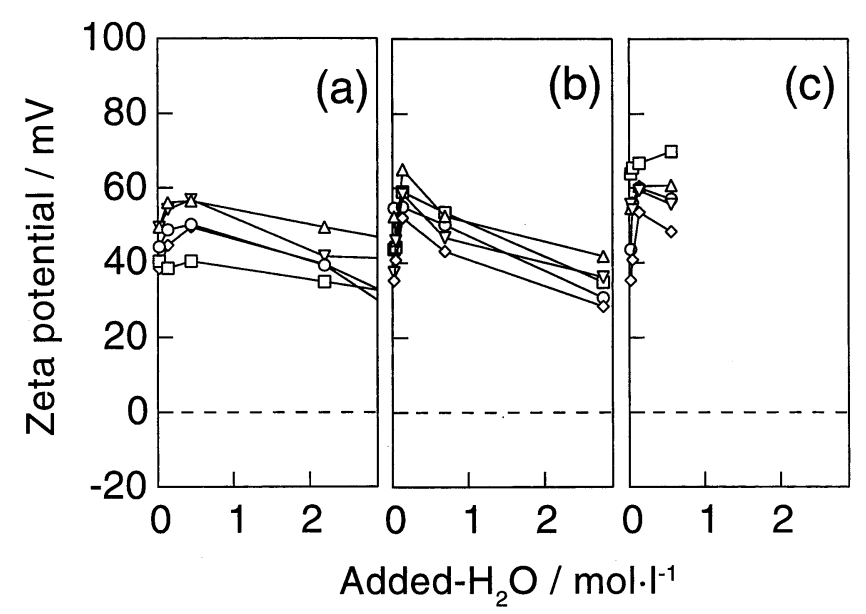

Fig. 5. Change of the zeta potential of various oxide powders with the amount of added $-\mathrm{H}_{2} \mathrm{O}\left(\mathrm{I}_{2}: 7.88 \times 10^{-4} \mathrm{~mol} / \mathrm{l}\right)$. (a) acetone, (b) methylethylketone, (c) cyclohexanone, oxide powder: $20 \mathrm{~g} / 1$, $\bigcirc: \mathrm{MgO}, \square: \mathrm{Al}_{2} \mathrm{O}_{3}, \triangle: \mathrm{Cr}_{2} \mathrm{O}_{3}, \nabla: \mathrm{TiO}_{2}, \diamond: \mathrm{WO}_{3}$.

tion is dilute, the $\mathrm{H}^{+}$ion is preferentially adsorbed onto the oxide particles. ${ }^{2)}$ Consequently, the zeta potential increased with increasing ion concentration. If the ion concentration is further increased, the zeta potential decreased because of the compression of the electrical double layer. ${ }^{2)}$ The $\mathrm{H}_{2} \mathrm{O}$ is needed as a catalyst, however, it seems that the extra amount of $\mathrm{H}_{2} \mathrm{O}$ before the phase separation influences the compression of the electrical double layer. Therefore, the zeta potential curve has a maximum as a function of $\mathrm{H}_{2} \mathrm{O}$ concentration. In the case of the $\mathrm{I}_{2}$ and $\mathrm{H}_{2} \mathrm{O}$-added cyclohexanone bath, the amount of $\mathrm{H}^{+}$ion adsorbed is higher than that for the other baths. As a result, the order of the zeta potential for various kinds of oxides became acetone $<$ methylethylketone $<$ cyclohexanone as shown in Figs. 4 and 5.

3.1.2 Zeta potential and electronegativity of metal ion in oxide

In Figs. 4 and 5, the zeta potential in the same solvent is different with the kind of oxides. In Fig. $1, \mathrm{H}^{+}$ion is adsorbed on the oxygen in hydroxyl group. This is based on the model of the solid acid-base of an oxide; the basicity of the oxide depends on the electronegativity of the metal ion. Therefore, we investigated the relation between the zeta potential and electronegativity of a metal ion in an oxide. The adsorption of $\mathrm{H}^{+}$ion in the solvent affects the partial charge density of oxygen in the hydroxyl group, which is polarized $\mathrm{M}\left(\delta^{+}\right)-\mathrm{O}\left(\delta^{-}\right)$. The adsorbing strength is changed with electronegativity of the metal ion in the oxide. In the case of a low electronegativity of a metal ion, the negative charge density of the oxygen on the oxide surface is large. Therefore, $\mathrm{H}^{+}$ion is adsorbed onto the oxide surface and the zeta potential becomes large or changes to positive.

The partial charge density of oxygen on the oxide surface increases with decreasing electronegativity of the metal ion (Fig. 6). ${ }^{10)}$ Figure 7 shows the relation between the electronegativity of the metal ion and the zeta potential of the oxide in the $\mathrm{I}_{2}$-added acetone bath. ${ }^{5}$ ) The zeta potential of an oxide increased with decreasing electronegativity of the metal ion. Consequently, in the case of the $\mathrm{H}^{+}$ion as the potential determining ion, it is considered that the zeta potential of the oxide is influenced by the electronegativity of the metal ion.

\subsection{Zeta potential in alcohol baths}

In the case of the $\mathrm{I}_{2}$-added ketone bath, $\mathrm{H}^{+}$ion behaves as the potential determining ion, and the zeta potential is in-

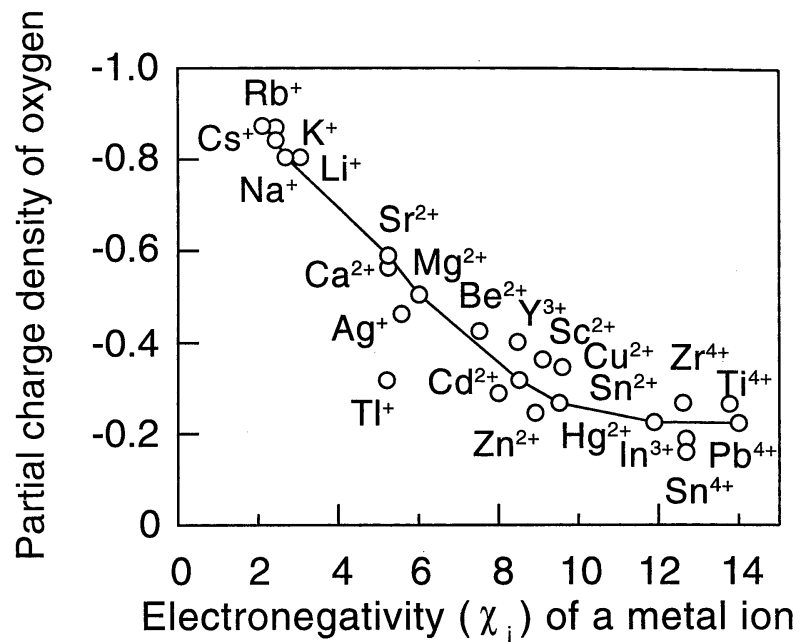

Fig. 6. Relation between a partial charge density of oxygen in the oxide and electronegativity $\left(\chi_{\mathrm{i}}\right)$ of a metal ion. ${ }^{9)}$

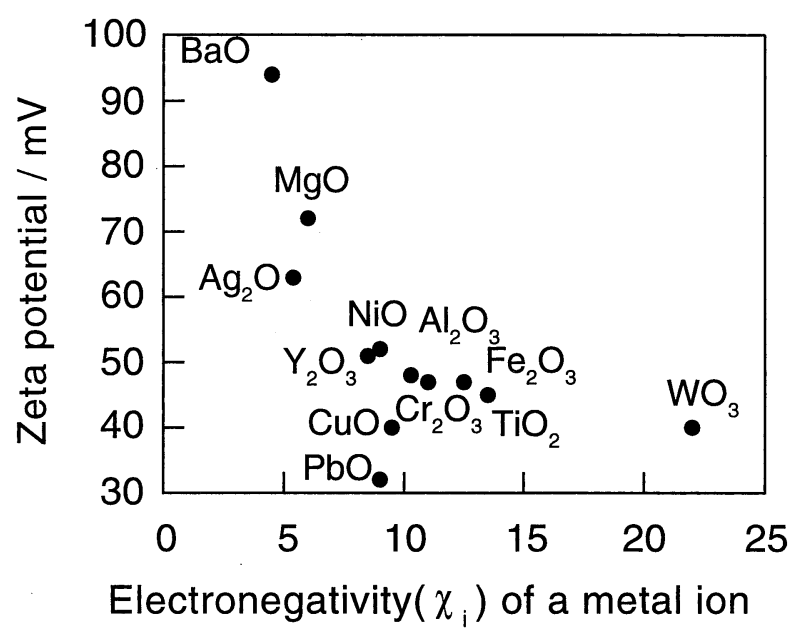

Fig. 7. Relation between zeta potential of an oxide in acetone bath $\left(\mathrm{I}_{2}: 3.94 \times 10^{-3} \mathrm{~mol} / \mathrm{l}\right)$ and electronegativity $\left(\chi_{\mathrm{i}}\right)$ of a metal ion. ${ }^{5)}$

fluenced by the electronegativity of the metal ion in the oxide. We investigated the relation between electronegativity and charging mechanism due to the adsorption of $\mathrm{H}^{+}$ion in a protic solvent like an alcohol. A small amount of $\mathrm{H}_{2} \mathrm{O}$ in the alcohol generated $\mathrm{H}^{+}$and $\mathrm{OH}^{-}$by electrolytic dissociation. In the case of the $\mathrm{H}^{+}$ion, it behaves the potential determining ion, and the zeta potential is influenced by adsorption of $\mathrm{H}^{+}$ion onto the oxide in organic solvents like an alcohol.

In Fig. 8, the electronegativity of the metal ion in oxides becomes small, and the zeta potential becomes large in EtOH regardless of the $\mathrm{H}_{2} \mathrm{O}$ content being the same as in Fig. 7.

Figure 9 shows the relation between the zeta potential in several alcohols and the electronegativity of the metal ion. As the electronegativity of the metal ion in the oxides becomes small, the zeta potential becomes large regardless of the alcohol. The order of the zeta potential in solvents is $1-\mathrm{BuOH}>1-\mathrm{PrOH}>\mathrm{EtOH}$. This order is the same as the value of the relative dielectric constant (Table 1).6) It has been assumed that the $\mathrm{H}^{+}$ion tends to adsorb on the oxide in the relatively small dielectric constant bath, because the $\mathrm{H}^{+}$ion is difficult to exist in the solvent. Moreover, it is necessary to study in the future the dissociation of $\mathrm{H}^{+}$ion 


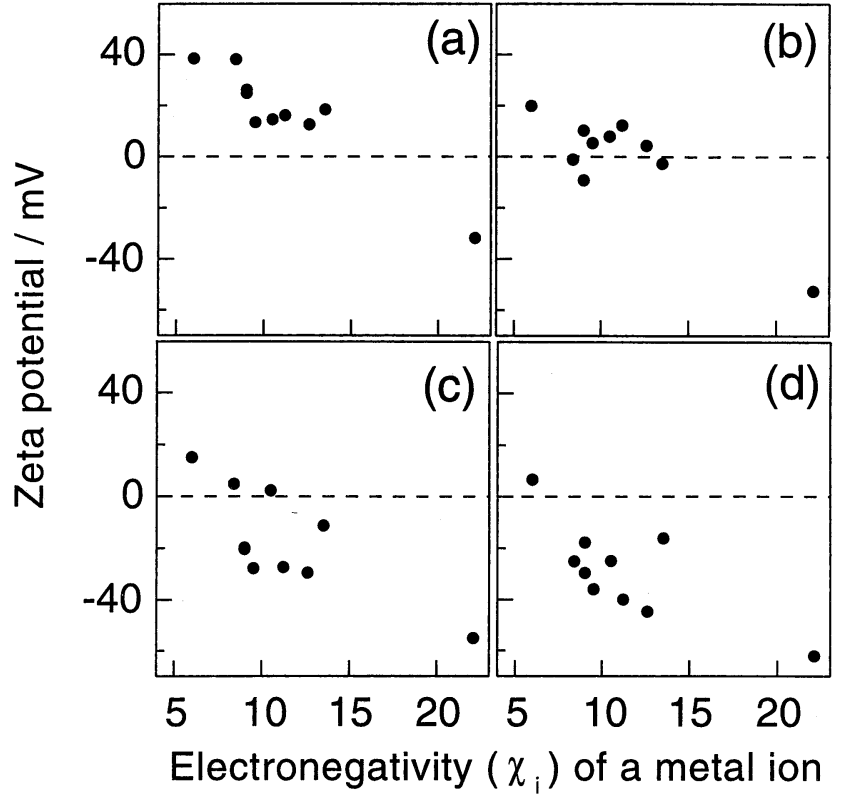

Fig. 8. Relation between zeta potential of oxide particles and electronegativity $\left(\chi_{\mathrm{i}}\right)$ of a metal ion in ethanol bath. $\mathrm{H}_{2} \mathrm{O}$ : (a) $5.56 \times 10^{-1}$, (b) $1.67 \times 10^{-1}$, (c) $2.13 \times 10^{-2}$, (d) $1.41 \times 10^{-2}$ $\mathrm{mol} / 1$.

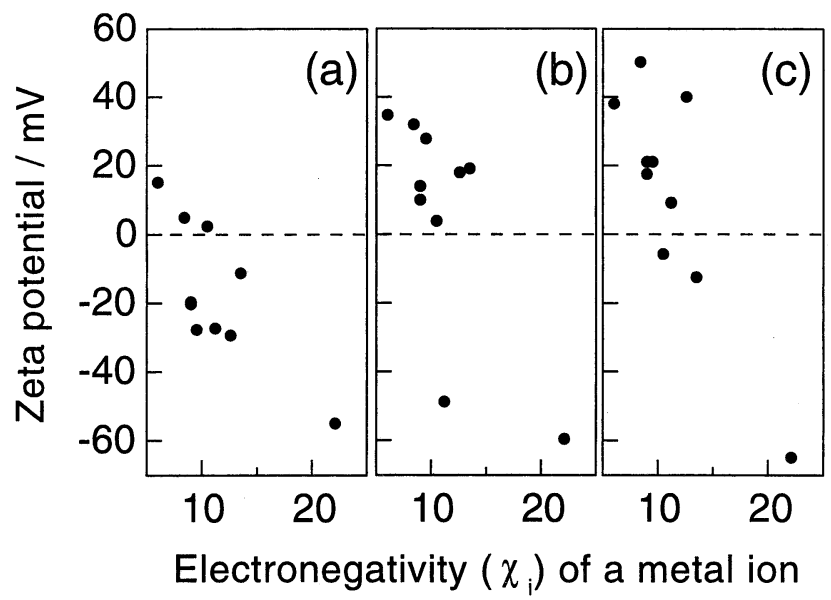

Fig. 9. Relation between zeta potential of oxide particles and electronegativity $\left(\chi_{\mathrm{i}}\right)$ of a metal ion. $\mathrm{H}_{2} \mathrm{O}: 2.13 \times 10^{-2} \mathrm{~mol} / 1$, (a) $\mathrm{EtOH}$, (b) 1-PrOH, (c) 1-BuOH, oxide powder: $20 \mathrm{~g} / 1$. from alcohol.

As a result, in the case of the $\mathrm{H}^{+}$ion, it behaved as the potential determining ion in alcohols, and it has been assumed that the determination of the zeta potential is affected by the electronegativity of the metal ion and dielectric constant of solvent. These results are similar to that of the $\mathrm{I}_{2}$-added ketone baths.

\section{Conclusions}

The charging behavior and the zeta potential of various oxide particles were investigated in various $\mathrm{I}_{2}$-added ketone baths and $\mathrm{EtOH}, 1-\mathrm{PrOH}$ and $1-\mathrm{BuOH}$. In the $\mathrm{I}_{2}$-added ketone baths, as the percent of the enol-type increases, $\mathrm{H}^{+}$ ion concentration increases. If the electronegativity of the metal ion in oxides is lower, the zeta potential becomes large. The order of the zeta potential is cyclohexanone $>$ methylethylketone >acetone; this order is the same as the amount of $\mathrm{H}^{+}$ion adsorbed. In protic solvents such as $\mathrm{EtOH}, 1-\mathrm{PrOH}$ and $1-\mathrm{BuOH}$, the electronegativity of the metal ion in oxides is lower, and the zeta potential also becomes larger. The zeta potential of the oxides in these alcohols depends on the dielectric constant of the solvents and the $\mathrm{H}_{2} \mathrm{O}$ concentration in the baths. In conclusion, $\mathrm{H}^{+}$ ion behaves as a potential determining ion, and the zeta potential is changed by the amount of $\mathrm{H}^{+}$ion adsorbed on the oxide surface, which is influenced by the electronegativity of the metal ion.

Acknowledgment This study was partly supported by an R\&D program of the New Energy and Industrial Technology Development Organization (NEDO). The authors would like to thank Dr. Nobuhiro Muramatsu of our university for the zeta potential measurements of the oxide particles.

\section{References}

1) N. Koura, T. Tsukamoto, H. Shoji and H. Negishi, Hyomen Gijutsu, 46, 533-38 (1995).

2) A. Kitahara, K. Furusawa, M. Ozaki and H. Oshima, "Zeta Den-i," Saientisuto-sha, Tokyo (1995).

3) Y. Tokuoka, T. Kishi and T. Nagai, Denki Kagaku, 42, 80-84 (1974).

4) J. Mizuguchi, K. Sumi and T. Muchi, J. Electrochem. Soc., 130, 1819-25 (1983).

5) N. Koura, T. Tsukamoto, H. Shoji and T. Hotta, Jpn. J. Appl. Phys., 34, 1643-47 (1995).

6) "Kagaku Binran Kisohen," Nippon Kagaku-kai, Maruzen, Tokyo (1975)

7) N. Koura and Y. Mikuriya, Hyomen Gijutsu, 40, 819-24 (1989).

8) Y. Arai, "Funtai no Zairyo Kagaku," Baifukan, Tokyo (1987) p. 52

9) S. J. Rhoads and C. Pryde, J. Org. Chem., 30, 3212-14 (1965).

10) K. Tanaka, “Shokubai Kogaku Koza, 10," Chijin Shokan, Tokyo (1967) p. 787 